\title{
Corrigendum
}

\section{Folate intakes from diet and supplements may place certain Canadians at risk for folic acid toxicity - CORRIGENDUM}

Adriana N. Mudryj ${ }^{1^{*}}$, Margaret de Groh ${ }^{2}$, Harold M. Aukema ${ }^{1}$ and Nancy Yu ${ }^{1,3}$

(First published online 9 September 2016)

doi: 10.1017/S0007114512004369, Published by Cambridge University Press, 9 October 2012.

\section{Acknowledgements}

The authors thank Dr Amanda MacFarlane at Nutrition Research Division, Health Canada, for her thorough review and constructive suggestions for this paper and Linda Greene-Finestone from the Public Health Agency of Canada for her assistance and suggestions.

\section{Correction:}

Dr Amanda MacFarlane and Linda Greene-Finestone request that their names be removed from the Acknowledgements section of this article. 